\title{
Demonstration of the Cascadia G-FAST Geodetic Earthquake Early Warning System for the Nisqually, Washington, Earthquake
}

\section{by Brendan W. Crowell, David A. Schmidt, Paul Bodin, John E. Vidale, Joan Gomberg, J. Renate Hartog, Victor C. Kress, Timothy I. Melbourne, Marcelo Santillan, Sarah E. Minson, and Dylan G. Jamison}

\begin{abstract}
A prototype earthquake early warning (EEW) system is currently in development in the Pacific Northwest. We have taken a two-stage approach to EEW: (1) detection and initial characterization using strong-motion data with the Earthquake Alarm Systems (ElarmS) seismic early warning package and (2) the triggering of geodetic modeling modules using Global Navigation Satellite Systems data that help provide robust estimates of large-magnitude earthquakes. In this article we demonstrate the performance of the latter, the Geodetic First Approximation of Size and Time (G-FAST) geodetic early warning system, using simulated displacements for the $2001 M_{\mathrm{w}} 6.8$ Nisqually earthquake. We test the timing and performance of the two G-FAST source characterization modules, peak ground displacement scaling, and Centroid Moment Tensor-driven finite-fault-slip modeling under ideal, latent, noisy, and incomplete data conditions. We show good agreement between source parameters computed by G-FAST with previously published and postprocessed seismic and geodetic results for all test cases and modeling modules, and we discuss the challenges with integration into the U.S. Geological Survey's ShakeAlert EEW system.
\end{abstract}

\section{INTRODUCTION}

Earthquake early warning (EEW) systems provide seconds to minutes of advanced warning after rupture initiation and prior to the arrival of strong ground shaking at a location. The methodology currently employed uses seismic networks to quickly characterize the magnitude and epicenter from $P$ waves at the stations nearest to the epicenter and sends an alert over a broad region before the $S$ wave arrives. A common problem with seismically derived magnitudes for EEW is the saturation of the signal at large magnitudes ( $\mathbf{M}>7$; Brown et al., 2011). One cause of saturation is the limited $P$-wave time window available for analysis before the arrival of the $S$ wave at nearby stations, which can be shorter than the duration of the rupture source for large events. Another culprit in magnitude saturation is the high-pass filtering of strong-motion records, which is performed to min- imize long-period drifts due to sensor rotations and tilts during integration to velocity and displacement (Melgar, Bock, et al., 2013). This filtering reduces the low-frequency content of the earthquake recording, which is critical to characterize large earthquakes.

Geodetic observations provide an additional constraint that does not saturate for large-magnitude events. Global Positioning System (GPS) displacement waveforms on their own have been shown to be useful for near-real-time magnitude determination using peak ground displacement (PGD) scaling relationships (Crowell et al., 2013; Melgar et al., 2015), rapid Centroid Moment Tensor (CMT) determination for size and orientation (Melgar et al., 2012; Melgar, Crowell, et al., 2013; O'Toole et al., 2013), and finite-fault methods that use rapidly computed coseismic offsets to compute slip on the fault (Crowell et al., 2009, 2012; Allen and Ziv, 2011; Ohta et al., 2012; Wright et al., 2012; Böse et al., 2013; Colombelli et al., 2013; Minson et al., 2014; Grapenthin et al., 2014a). PGD scaling has been shown to be slower than $P$-wave-based methods because (1) large earthquakes take time to reach their peak amplitudes and (2) the $S$ waves that determine PGD travel little more than half the speed of $P$ waves. In the case of a large offshore event like the $2011 M_{\mathrm{w}} 9.0$ Tohoku-Oki earthquake, an initial PGD-based magnitude estimate of $\mathbf{M} 8.5$ would be available $50 \mathrm{~s}$ following nucleation, which still would have been useful for warning large population centers like Tokyo (Melgar et al., 2015). Methods that rely on coseismic offsets can have an impact on traditional EEW only in extreme cases (i.e., large earthquakes far from population centers with $S$-wave travel times on the order of a few minutes or preferential geometrical alignment of stations), but their major utility is in proper characterization of earthquake impact for tsunami early warning and hazard response (Blewitt et al., 2006; Ohta et al., 2012). In addition, Crowell et al. (2013) have shown that when strong-motion accelerations and GPS displacements are combined using a multirate Kalman filter (Bock et al., 2011), the impact of magnitude saturation is greatly diminished, even using only the first $5 \mathrm{~s}$ of data after the $P$-wave arrival. This method requires collocated GPS and strong- 
motion instruments, which is currently rare in western North America.

The subduction environment of Cascadia motivates the need for a joint seismic and geodetic EEW system to rapidly characterize all possible earthquakes within the region. Potential events include large megathrust events and outer-rise events anywhere from the Mendocino triple junction to Vancouver Island, shallow crustal earthquakes in the Seattle and Portland metropolitan areas, and deep events within the slab. At the University of Washington (UW), development of the Geodetic First Approximation of Size and Time (G-FAST) system has been a high priority for operational EEW in the Cascadia region.

G-FAST continuously receives real-time processed GPS time series from the Pacific Northwest Geodetic Array (PANGA) and maintains a local data buffer. G-FAST receives event triggers from a seismic detection module, such as Earthquake Alarm Systems (ElarmS), and starts with an estimate of the location, timing, and size of the earthquake. G-FAST first estimates magnitude and depth from PGD scaling. It then invokes a modeling suite to estimate a CMT and finite-fault parameters.

To explore the performance of the system, we implemented a test system that reads in synthetic data and $\mathrm{xml}$ messages from a seismic detection module and outputs the information in a simulated real-time mode, leaving the back-end modeling modules untouched. The simulated system allows us to vary the latency, data completeness, and noise to test the robustness of magnitude, timing, and slip estimates from G-FAST.

In this article, we first give an overview of G-FAST and the synthetic test system. Then, we demonstrate the performance during a simulation of the 28 February $2001 M_{\mathrm{w}} 6.8$ Nisqually earthquake. The Nisqually earthquake was a deep intraslab event located at the southern end of Puget Sound, roughly $50 \mathrm{~km}$ deep, and caused damage costing several billion dollars in the Seattle area (Ichinose et al., 2004). The Nisqually earthquake is a good test case for G-FAST, because intraplate events have a higher probability of occurrence in the Pacific Northwest than a megathrust event ( $\sim 30-50$ year recurrence, with the prior comparable 1949 Olympia and 1965 Seattle-Tacoma events, Ichinose et al., 2004), and it caused shaking over a wide region (modified Mercalli intensity [MMI] VI-VII throughout the Puget Lowlands, see Data and Resources), and was recorded with fairly low signal-to-noise surface displacements. The components of G-FAST have been independently tested and validated on much larger earthquakes elsewhere in Japan, Chile, Indonesia, and southern California (Crowell et al., 2012, 2013; Melgar et al., 2012, 2015); so the motivation for testing G-FAST on the Nisqually earthquake is to determine the performance and resolution toward the lower end of detectability and to ascertain statistics on the range of possible solutions by varying the latency, noise, and data completeness. Finally, we discuss how to best improve the EEW system based on the simulation results and challenges associated with integration into the ShakeAlert system, which is the EEW system currently under development by the U.S. Geological Survey (USGS) with university partners (Given et al., 2014).

\section{JOINT EARTHQUAKE EARLY WARNING SYSTEM}

The current ShakeAlert system uses three different seismic algorithms for estimating location, magnitude, and origin time (OT): ElarmS (Kuyuk et al., 2014), Virtual Seismologist (VS, Cua and Heaton, 2007), and OnSite (Böse et al., 2009). The California system runs all three algorithms, whereas the Pacific Northwest system currently only uses ElarmS. Several GPSbased algorithms that utilize rapidly computed coseismic offsets are currently under development, including G-larmS (Grapenthin et al., 2014a) and BEFORES (Minson et al., 2014). In this article, we document an additional geodetic module under development, G-FAST. What distinguishes the G-FAST approach is its combination of different types of analyses. It first estimates source depth and magnitude from PGD. This is similar to GPSlip (Böse et al., 2013), which also determines source strength from PGD, but with the addition of solving for source depth as well, giving G-FAST an advantage in subduction zone environments where earthquakes occur over a wide range of depths. G-FAST then uses a geodetically derived focal mechanism to determine the fault orientation, builds a discretized fault plane with that orientation, and then inverts for the static slip distribution on that fault plane. This final slip model is as complex as the BEFORES geodetic EEW algorithm (Minson et al., 2014), which rapidly updates both the fault orientation and the spatial distribution of accumulated slip on that fault plane as the rupture evolves, and is more complex than the GlarmS geodetic EEW source model (Grapenthin et al., 2014a), which only allows for along-strike variations in slip amplitude. Thus, the G-FAST slip model is probably better suited than GlarmS to subduction zone earthquakes that can have significant along-dip variation in slip. The G-FAST approach is also substantially faster than G-larmS because we can obtain the PGDdetermined magnitude and source depth before the wavefield has converged to the static state, and it is probably comparable in speed to BEFORES, although direct head-to-head performance testing between the various geodetic EEW algorithms has yet to be done. The flowchart of operations of G-FAST is shown in Figure 1. The system consists of two independent packages: (1) a data aggregator and buffer that runs continuously and (2) a triggered modeling suite that activates upon receiving an alert from the seismic warning system (currently ElarmS). High-rate real-time GPS positions are continuously received at the Pacific Northwest Seismic Network (PNSN) from PANGA through the JSON protocol (see Data and Resources). The PANGA solutions are integer ambiguityresolved precise point positions (Zumberge et al., 1997) estimated at $1 \mathrm{~s}$ epochs within the ITRF2008 reference frame (Altamimi et al., 2012) using satellite orbit and clock corrections provided by the International Global Navigation Satellite Systems Service. Station positions are estimated independently and do not depend on a fixed reference station or network. 


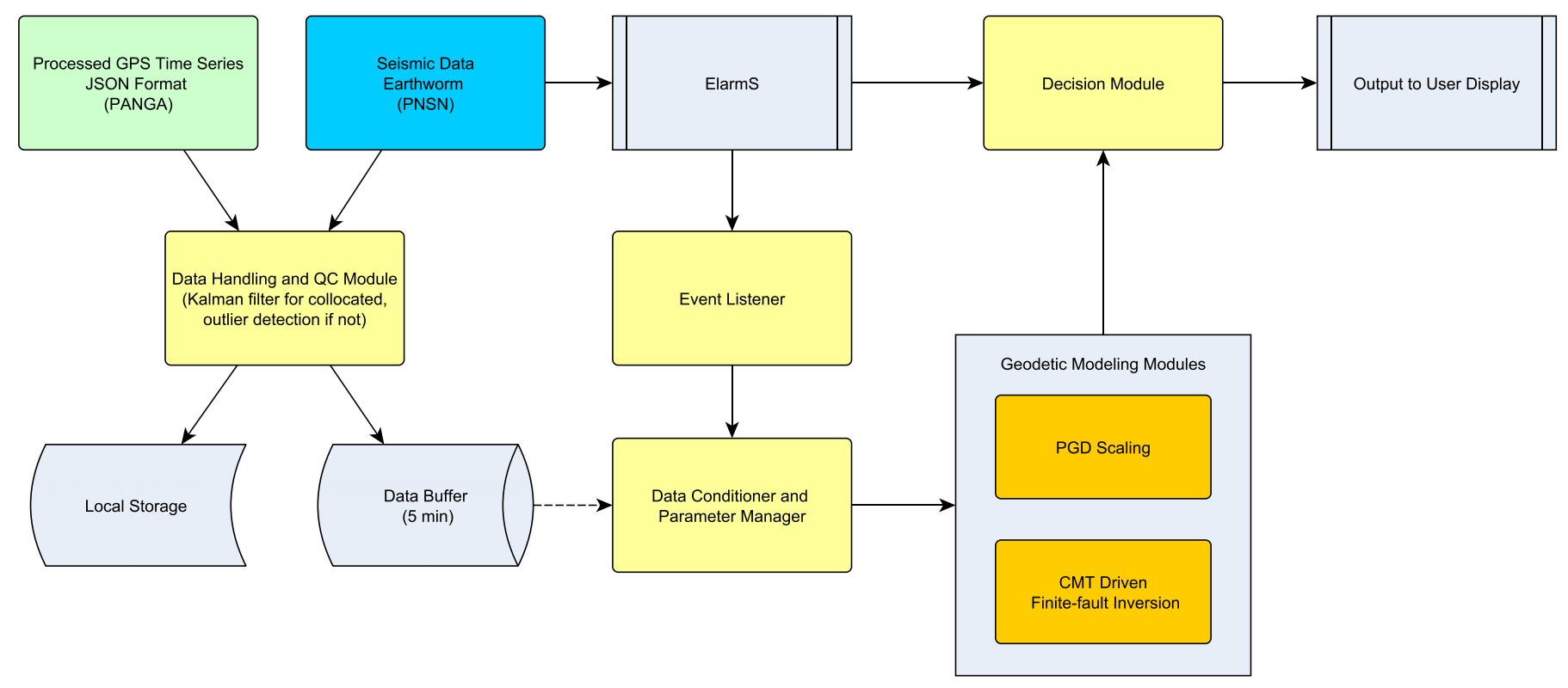

A Figure 1. Flowchart of proposed joint early warning system with Geodetic First Approximation of Size and Time (G-FAST) and seismic algorithms (Earthquake Alarm Systems [ElarmS]). The color version of this figure is available only in the electronic edition.

We maintain a continuous 5 -min data buffer as well as archive data at UW.

ShakeAlert's ElarmS software continuously scans strong motion and broadband data from the PNSN and other nearby seismic networks for possible $P$-wave arrivals. When ElarmS identifies a possible event at four seismic stations, it determines an epicenter, OT, and magnitude with the first $4 \mathrm{~s}$ or less of data after the $P$-wave arrival at each station. ElarmS computes peak displacements 10 times per second and updates magnitude and epicenter as more stations report arrivals. When an M 3.0 or greater event is reported, the geodetic modeling modules are initiated using the OT and epicenter from ElarmS. This magnitude is well below the noise threshold of detection with real-time GPS $(\mathbf{M} \sim 6)$, but we choose to trigger on all events reported by the seismic warning system. The PGD module estimates magnitude and depth once four GPS stations are within a $3-\mathrm{km} / \mathrm{s}$ travel-time mask and updates these estimates every second. The CMT-derived finite-fault inversion waits until static offsets $(1-\mathrm{km} / \mathrm{s}$ travel-time mask with $10 \mathrm{~s}$ of averaging) are in hand to compute an estimate of fault orientation, magnitude, depth, and slip along the fault surface. The source models from both modules will be fed into a joint seismic/geodetic ShakeAlert DecisionModule that, although yet to be developed, will combine the information from all of the contributing EEW algorithms to produce a unified shaking forecast. This shaking forecast would then be sent to end users.

\section{DATA FROM THE 2001 NISOUALLY EARTHOUAKE}

At the time of the Nisqually earthquake, the PNSN consisted of 26 strong-motion stations in the region (Fig. 2). The PANGA network consisted of $\sim 15$ permanent GPS stations within the epicentral region (Bustin et al., 2004), although none of these were capable of recording high-rate data (1 Hz or greater). Because of this, we supplement the strong-motion recordings with a set of synthetic displacement waveforms at the locations of the 26 strong-motion stations, computed up to $5 \mathrm{~Hz}$ using the frequency-wavenumber $(f-k)$ integration method (Zhu and Rivera, 2002). The method sums the waves radiated from an array of point sources on a predefined fault to model waveforms. The fault we use is centered on the PNSN hypocenter location $\left(47.149^{\circ} \mathrm{N}, 122.727^{\circ} \mathrm{W}, 51.9 \mathrm{~km}\right.$ deep) with a strike of $350^{\circ}$, dip of $70^{\circ}$, rake of $-90^{\circ}$, length of $23 \mathrm{~km}$, width of $10 \mathrm{~km}$, and magnitude 6.8 (Bustin et al., 2004). For the seismicvelocity structure, we use the standard layered half-space model that is used by the PNSN to locate earthquakes in Puget Sound. The shear modulus is assumed to be $66 \mathrm{MPa}$ in the seismic source region (Bustin et al., 2004).

The amplitudes and timing of the synthetic velocity waveforms are in qualitative general agreement with the recorded seismic waveforms, although precise matches were not achieved nor needed for our purposes. The peak velocity root mean square (rms) difference between the synthetics and the data was $0.05 \mathrm{~m} / \mathrm{s}$ across 69 channels, and $60 \%$ of the synthetic channels achieved peak velocity within $5 \mathrm{~s}$ of the data. For our synthetic source model, a constant fault slip of $1.4 \mathrm{~m}$ is assigned across the fault plane with a rupture front that propagates from the hypocenter at $3.2 \mathrm{~km} / \mathrm{s}$. We did not attempt to account for any additional complexity of the rupture, which might better emulate the observed waveforms. For G-FAST, a simpler source is sufficient because the largest impact on source estimation will be the amplitudes of the displacement waveforms, the timing of the peak displacement, and the time in which the static offset is fully emplaced. The predicted synthetic displacements agree 


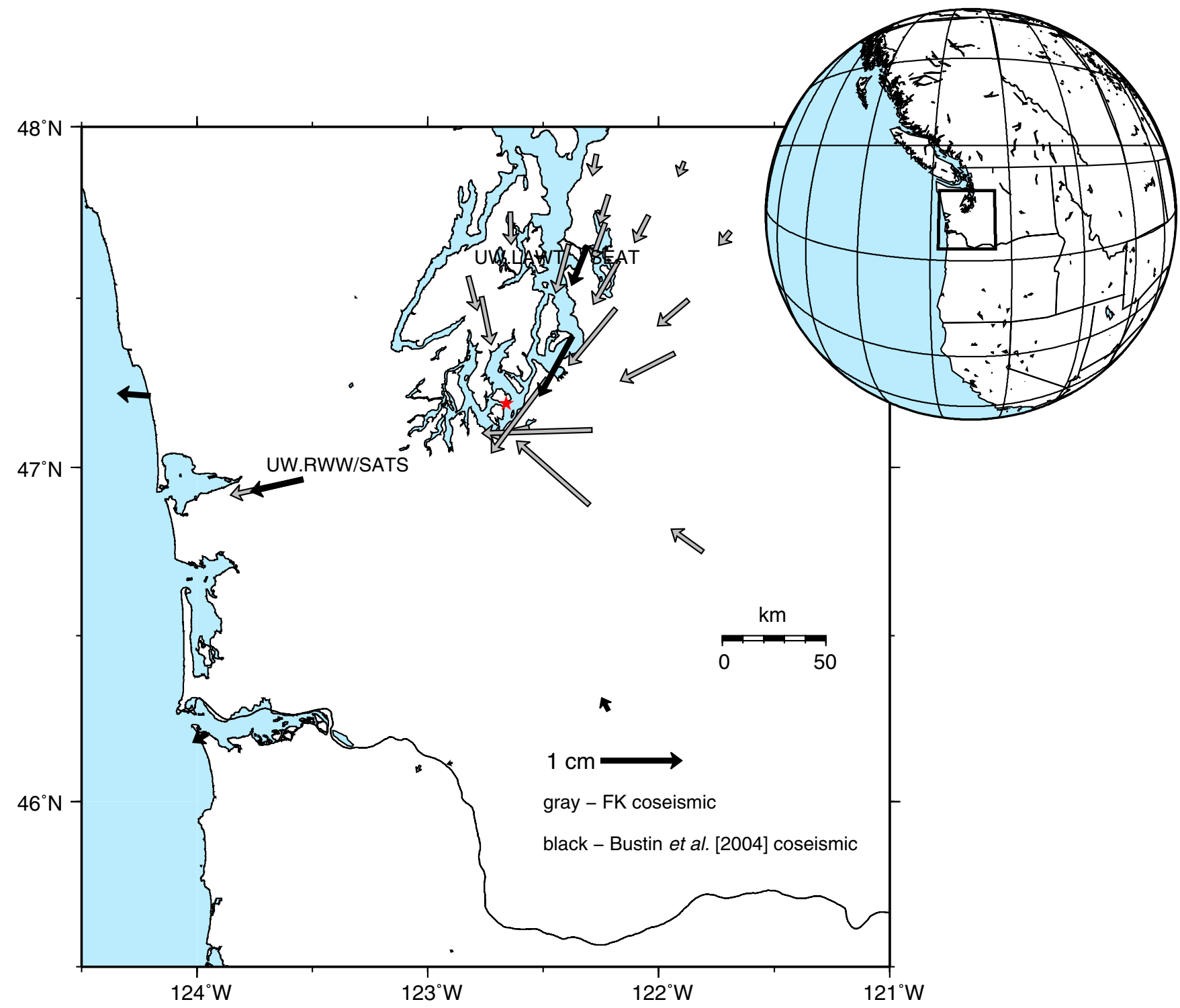

A Figure 2. The gray vectors indicate the location of the strong-motion stations used in this study as well as their associated coseismic displacements. The black vectors are coseismic displacements computed from Bustin et al. (2004). The star indicates the location of the epicenter. Note that three of the strong-motion stations are outside of the map. The color version of this figure is available only in the electronic edition.

well with the observed static displacements from GPS (Bustin et al., 2004). Figure 2 shows the coseismic displacements from the synthetics (gray arrows) and the observed offsets determined by Bustin et al. (2004) (black arrows). Although there were not many GPS stations at the time, GPS station SATS is collocated with strong-motion station UW.RWW, and GPS station SEAT is $6.1 \mathrm{~km}$ from strong-motion station UW.LAWT. The three-component rms differences between simulated and measured coseismic displacements at these two stations are 2.82 and $1.35 \mathrm{~mm}$, respectively, and other GPS stations in the region show a similar pattern of deformation to our synthetic coseismic displacements. We only use simulated displacements from the subset of 26 operational strong-motion stations in 2001 because ground motions were validated only at those stations.

\section{GEODETIC MODELING MODULES}

\section{Peak Ground Displacement}

Crowell et al. (2013) presented the scaling of PGD as a function of hypocentral distance for earthquakes between M 5.4 and 9.0. They found the following relationship:

$$
\log _{10}(\mathrm{PGD})=A+B M_{\mathrm{w}}+C M_{\mathrm{w}} \log _{10}\left(r_{\mathrm{hyp}}\right) \text {, }
$$

in which $r_{\text {hyp }}$ is the hypocentral distance in kilometers, $M_{\mathrm{w}}$ is the moment magnitude, PGD is the maximum of the Euclidian norm of the three components of displacement (north, east, and vertical) in centimeters, and $A, B$, and $C$ are the constants solved through a regression of previous data. The following inverse problem is set up to solve for magnitude: 

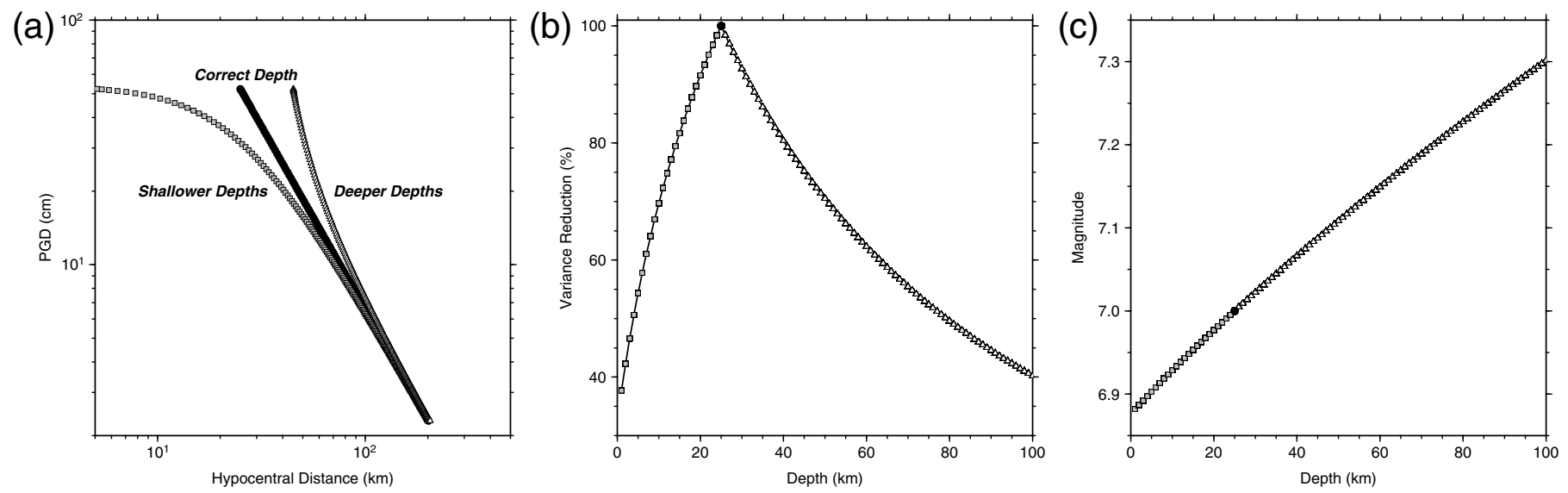

A Figure 3. (a) The predicted peak ground displacement (PGD) for an $\mathbf{M} 7.0$ earthquake at a depth of $25 \mathrm{~km}$ (correct depth in figure and black circles). The gray squares and white triangles show how the curve would change for different assumed depths ( $5 \mathrm{~km}$ for shallower, $45 \mathrm{~km}$ for deeper). (b) The variance reduction (VR) as a function of depth for the PGD regression for the same earthquake. In this example, at $25 \mathrm{~km}$ the VR is 100\%, meaning that the model (log-log linearity) fits the data perfectly. (c) The inverted magnitude as a function of depth.

$G M_{\mathrm{w}}=b$,

$G=\left[\begin{array}{c}B+C \log _{10}\left(r_{\mathrm{hyp}, 1}\right) \\ \vdots \\ B+C \log _{10}\left(r_{\mathrm{hyp}, n}\right)\end{array}\right], \quad b=\left[\begin{array}{c}\log _{10}\left(\mathrm{PGD}_{1}\right)-A \\ \vdots \\ \log _{10}\left(\mathrm{PGD}_{n}\right)-A\end{array}\right]$.

For G-FAST, we make a few key operational changes from Crowell et al. (2013). First, we introduce a travel-time mask of $3 \mathrm{~km} / \mathrm{s}$ given the earthquake OTs from ElarmS that ignores all stations outside of the travel-time mask at a given time. Second, no magnitudes are estimated for fewer than four stations. Third, we utilize exponential distance weighting of the form:

$w_{i}=\exp \left(-\frac{r_{\mathrm{epi}, i}^{2}}{8 r_{\mathrm{ep}, \min }^{2}}\right)$

in which $r_{\text {epi, } i}$ is the epicentral distance in kilometers of the $i$ th station and $r_{\text {epimin }}$ is the epicentral distance of the closest station. The distance weighting in equation (4) is a function of the epicentral distance, so as not to bias the depth grid search discussed later toward shallower solutions. The factor of 8 in the denominator is arbitrarily chosen through trial and error to give relatively high weight to many close stations before dropping off exponentially. The magnitude is then found by solving

$\mathbf{W} G M_{\mathbf{w}}=\mathbf{W} b$,

in which $\mathbf{W}$ is a diagonal matrix of station weights $w_{i}$. We recalibrate the regression constants of Crowell et al. (2013) with the inclusion of the distance weight matrix using data for the Tohoku-Oki, Tokachi-Oki, and El Mayor-Cucapah earthquakes. We find $A=-6.687, B=1.500$, and $C=-0.214$, with an improved magnitude uncertainty of 0.17 magnitude units. These coefficients are different from an analysis by Melgar et al. (2015) using an expanded data set of 10 earthquakes recorded by GPS alone. The recalibration of the Crowell et al. (2013) regression uses only seismogeodetic (collocated GPS and strong-motion stations) data and hence represents a minimal noise solution. However, in general, all the regression solutions predict similar magnitudes within the bounds of uncertainty of the method ( \pm 0.3 magnitude units).

Finally, we introduce a grid search for the earthquake depth. ElarmS assumes a depth of $8 \mathrm{~km}$ for all events, because that is the average seismogenic depth in California. But the PGD algorithm requires proper depth characterization, given that the depth affects the PGD pattern. It is also important to discriminate between shallow crustal earthquakes and deeper events that are located along the plate interface or within the slab. The grid-search method simply computes the magnitude at $1 \mathrm{~km}$ intervals between 0 and $100 \mathrm{~km}$ depth and chooses the depth that maximizes the variance reduction (VR) defined by

$\mathrm{VR}=\left(1-\frac{\left\|b-G M_{\mathrm{w}}\right\|}{\|b\|}\right) \times 100$.

We demonstrate this depth-dependent grid-search approach for a hypothetical $\mathbf{M} 7.0$ earthquake at $25 \mathrm{~km}$ depth (Fig. 3). We use the scaling relationship of equation (1) to find the PGD at a number of hypocentral distances, given a $25-\mathrm{km}$ depth. Then, we recompute the hypocentral distances based on different depths (between 1 and $100 \mathrm{~km}$ ), invert for the magnitude, and compute the VR of the inversion. In a perfect case, the PGD versus distance plot will be linear in log-log space, shown as correct depth in Figure 3a. For shallower and deeper depths, the PGD-distance curve (Fig. 3a) is no longer linear on a $\log -\log$ plot, so a straight line will never fit the data perfectly; this is seen in Figure $3 \mathrm{~b}$ where the $25 \mathrm{~km}$ depth yields a perfect $100 \%$ VR and all other depths fit the model worse. Figure 3c shows how the assumption of depth will change the magnitude estimate. For this hypothetical earthquake, changing the source 
depth for $1-100 \mathrm{~km}$ will change the magnitude by $0.4 \mathrm{mag}$ nitude units. Although this magnitude change is not large, the prediction of the strength of expected ground shaking is sensitive to different source depths.

\section{CMT-Driven Slip Modeling on a Finite Fault}

Computing the CMT is important, because it allows us to determine the fault orientation and location as well as magnitude, which have important implications for expected ground motions and tsunami potential. Melgar et al. (2012) showed how to compute the CMT using rapidly computed static offsets in a layered half-space. For efficiency and simplicity, we chose to solve the problem in a homogeneous half-space using the static displacement field analytical solution for the moment tensor from Hashima et al. (2008) and the references therein. The general solution for the displacement field $u_{i}(x)$ for a given moment tensor $M_{p q}$ at a point $x$ from a source at point $\xi$ is given by

$$
\begin{aligned}
u_{i}(x)= & \frac{1}{8 \pi \mu R^{2}}\left[\gamma\left(3 \zeta_{i} \zeta_{p} \zeta_{q}-\zeta_{i} \delta_{p q}-\zeta_{p} \delta_{q i}-\zeta_{q} \delta_{i p}\right)\right. \\
& \left.+2 \zeta_{q} \delta_{i p}\right] M_{p q}
\end{aligned}
$$

in which $i, p$, and $q$ are the three Cartesian directions, $\gamma=(3 K+\mu) /(3 K+4 \mu), \mu$ and $K$ are the rigidity and bulk modulus, respectively, $\delta_{i p}$ is the Kronecker delta, $R$ is the sourcereceiver distance defined by

$R=\sqrt{\left(x_{1}-\xi_{1}\right)^{2}+\left(x_{2}-\xi_{2}\right)^{2}+\left(x_{3}-\xi_{3}\right)^{2}}$,

and the scaled source-receiver distance is

$\zeta_{i}=\frac{x_{i}-\xi_{i}}{R}$

The following inverse problem for $n$ stations is set up and solved with linear least squares

$$
\begin{aligned}
{\left[\begin{array}{c}
u_{1,1} \\
u_{2,1} \\
u_{3,1} \\
\vdots \\
u_{1, n} \\
u_{2, n} \\
u_{3, n}
\end{array}\right]=} & {\left[\begin{array}{cccccc}
G_{111,1} & G_{121,1} & G_{131,1} & G_{221,1} & G_{231,1} & G_{331,1} \\
G_{112,1} & G_{122,1} & G_{132,1} & G_{222,1} & G_{232,1} & G_{332,1} \\
G_{113,1} & G_{123,1} & G_{133,1} & G_{223,1} & G_{233,1} & G_{333,1} \\
\vdots & \vdots & \vdots & \vdots & \vdots & \vdots \\
G_{111, n} & G_{121, n} & G_{131, n} & G_{221, n} & G_{231, n} & G_{331, n} \\
G_{112, n} & G_{122, n} & G_{132, n} & G_{222, n} & G_{232, n} & G_{332, n} \\
G_{113, n} & G_{123, n} & G_{133, n} & G_{223, n} & G_{233, n} & G_{333, n}
\end{array}\right] } \\
& \times\left[\begin{array}{c}
M_{11} \\
M_{12} \\
M_{13} \\
M_{22} \\
M_{23} \\
M_{33}
\end{array}\right],
\end{aligned}
$$

with the Green's functions, $G_{i p q, n}$, being defined by equation (7). The displacements $u_{i, n}$ are the static offsets on each of the three directional components, which are computed by taking the average of the first $10 \mathrm{~s}$ of data that arrive after a travel-time mask of $1 \mathrm{~km} / \mathrm{s}$ is used. Note, displacements are with respect to the station position at the OT of the earthquake. This travel-time mask is overly conservative, but we want to minimize inclusion of any dynamic motions that may contaminate the static offset measurements and do not want to rely on some other metric to determine if the solution is stable. The displacements and Green's functions are both rotated into the radial, transverse, and vertical directions, and the moment tensor is decomposed into the main and auxiliary fault planes using the Python ObsPy package (see Data and Resources). Rather than performing a grid search for the centroid location, we use the epicentral location from ElarmS and only perform a grid search for the depth using the same VR maximization scheme as was done for PGD.

A slip inversion on a finite fault provides a more accurate characterization of the event when compared to a point source, especially given a potential large megathrust event in Cascadia. Melgar, Crowell, et al. (2013) outlined the difficulties of using a simple point-source approximation for computing the CMT from static offsets for the Tohoku-Oki earthquake. In that case, they found using a fixed hypocenter point source would lead to an accurate moment tensor solution; however, the model fit would be poor (VR $<50 \%)$ and could not be trusted in real time. A slip inversion on a finite fault does not have these issues if the fault plane is large enough, is in the correct region, and has reasonable strike and dip angles. Grapenthin et al. (2014a) investigated the slip inversion sensitivity to location and fault orientation errors. Although a general rule-of-thumb is difficult here, because this is highly dependent on the earthquake source and network geometry, they found that variations in location, dip, and strike become less important for deeper events, and for shallower events the orientations should be within $5^{\circ}$. Misplacement of the center of the fault can impact the magnitude error by up to 0.5 magnitude units within $20 \mathrm{~km}$.

For G-FAST's slip inversion, we use the method of Crowell et al. (2012) where the fault geometry is defined by the CMT, and the Green's functions are prescribed by Okada's formulation (Okada, 1985) in a homogeneous half-space. The center of the fault plane is defined by the ElarmS epicenter and the depth computed from the CMT. The along-strike and alongdip dimensions of the fault are defined by scaling relationships from Dreger and Kaverina (2000), based on the CMT magnitude. We are not concerned that the CMT magnitude may be an overestimate, because this will only make the potential slip surface larger; the inversion does not prescribe slip in areas if the data misfit does not call for it. The CMT-computed depth also will not greatly impact the result, because it defines the center of the fault and the along-dip dimension will cover the majority of the possible seismogenic zone. Of the two fault planes from the CMT, we pick the one that minimizes the misfit as the final solution. Laplacian regularization with a generalized smoothing parameter described in Crowell et al. (2012) is used. The static offsets used are the same as for the CMT inversion. 


\section{SIMULATIONS}

We first run G-FAST assuming no data latency and no data noise to find the ideal source characterization and timing with the synthetic displacements. The ElarmS location, timing, and magnitude are found using the actual strong-motion data because the short-term average/long-term average algorithm for detecting $P$-wave arrivals requires some level of noise to operate efficiently.

To obtain realistic operational system performance, we run four simulations and for each conduct 1000 trials of GFAST. The four simulations test the impacts of (1) randomly generated latencies, (2) high-rate GPS station noise, (3) data dropouts, and (4) latency + noise + dropouts. We perform these simulations to test the stability and robustness of the source solutions, obtain realistic timing and to see how each factor impacts the results for future improvements. We generate integer latencies from a Poisson distribution with a mean of 6 s. Data latency from the PANGA/Plate Boundary Observatory $(\mathrm{PBO})$ network is generally much better than this and is improving (phase and range distribution $<1 \mathrm{~s}$, processing and distribution $<3 \mathrm{~s}$ ); however, we choose a conservative estimate.

We generate the station noise using the power spectrum for $40-\mathrm{km}$ relative GPS positions from Genrich and Bock (2006), a combination of white $\left(f^{0}\right)$, flicker $(1 / f)$, and random-walk $\left(1 / f^{2}\right)$ noise. We choose to simulate noise instead of superimposing recorded noise time series from PANGA to have control over the range of potential noise sources. We compared the power spectra of the 10 most complete time series recorded at the PNSN in real time from PANGA on 15 September 2015 with the power spectra of Genrich and Bock (2006). At periods less than $10 \mathrm{~s}$, the PANGA real-time solutions matched perfectly with the Genrich and Bock (2006) power spectra. At periods between $5 \mathrm{~min}$ and $10 \mathrm{~s}$, the real-time power spectra are systematically lower than the simulation power spectra we use, indicating that the simulations in this article represent a worst-case scenario, especially at long periods.

The real-time data completeness rate for $\mathrm{PBO}$ in the Cascadia region is generally better than 95\% (D. Mencin, personal comm., 2015, UNAVCO). Most data dropouts are due to a few stations with less than ideal telemetry, but for the sake of argument, we assume a data return rate of $85 \%$ for all stations during our simulations. For a large earthquake, we are uncertain as to the telemetry robustness, and therefore we want to consider a worst-case scenario. For these simulations, we simply remove $15 \%$ of the data points at random each trial. We do not consider spatial or temporal correlation of dropouts even though a significant percentage of dropouts will be due to the temporary failure of a single telemetry path that may handle several stations. Even without explicitly considering spatially correlated dropouts, removing $15 \%$ of the data (when data completeness is generally much better than 95\%) from each station at random will explore the range of possible solutions, and the source parameters should be robustly estimated with 1000 trials.

\section{RESULTS}

\section{Peak Ground Displacement}

The evolution of PGD magnitude and depth estimates over time is shown in Figure 4 for the ideal case as well as the four simulations for the Nisqually earthquake. In the ideal case, the first magnitude estimates from PGD are available $17 \mathrm{~s}$ after the OT, trailing ElarmS by about $4 \mathrm{~s}$. The initial PGD magnitude estimate is $\mathbf{M} 6.47$ (at 17 s) and $\mathbf{M} 6.43$ for ElarmS (at 12.8 s). The arrival of strong shaking in Seattle, $60 \mathrm{~km}$ northwest of the epicenter, is at $23 \mathrm{~s}$ after OT, so ElarmS would provide a $10 \mathrm{~s}$ warning to Seattle and an updated warning from PGD is available $6 \mathrm{~s}$ prior to strong shaking. For both ElarmS and PGD, the magnitude estimates start out small and increase quickly over the first $\sim 10 \mathrm{~s}$ to their final stable magnitude estimate. In the ideal case, no PGD estimate is provided to locations within $51 \mathrm{~km}$ of the epicenter. The magnitude estimates over time do not vary much for the ideal case; the full range of magnitude estimates is 0.2 magnitude units. The stable magnitude estimate $(>30 \mathrm{~s})$ from PGD $(\mathbf{M} 6.7 \pm 0.3)$ and from ElarmS (M 6.9) are both close to the true magnitude of 6.8.

The depth estimate in the ideal case starts out shallow but quickly converges to the final solution of $52 \mathrm{~km}$, exactly the input model depth $(51.9 \mathrm{~km})$ and close to the Global CMT solution of $46.8 \mathrm{~km}$. ElarmS assumes a depth of $8 \mathrm{~km}$ because it was designed to represent the average seismogenic depth in California; this has an impact on the prediction of travel times of strong shaking as well as estimating ground motions in ShakeAlert. Assuming a $1 / r$ attenuation, the $8 \mathrm{~km}$ depth at an epicentral distance of $20 \mathrm{~km}$ would overestimate strong shaking by a factor of 2.5 versus the $50 \mathrm{~km}$ depth given the same magnitude earthquake. The assumption of a shallower depth would lead to a smaller PGD magnitude estimate, however, as demonstrated by Figure 3c. We plan on modifying ElarmS in the Pacific Northwest to accommodate a depth grid search, however, dealing with other aspects of tuning ElarmS for the region has taken precedence (Hartog et al., 2016; see Data and Resources).

All four simulations produce stable estimates of magnitude after about $30 \mathrm{~s}$, although the range of magnitude estimates prior to $30 \mathrm{~s}$ is less than a magnitude unit, and the range of solutions quickly narrows to $\sim 0.3$ magnitude units. Evidence of this tight distribution of magnitude estimates is shown in Figure 5, which contains histograms of the simulations at $30 \mathrm{~s}$ after OT. The impact of latency is minimal on the stability of magnitude, and its impact is concentrated toward the beginning of the earthquake, although latency is the only parameter that impacts the warning time. The average first-alert time in the latency simulations is $21.9 \mathrm{~s}$ after OT, which matches the $5 \mathrm{~s}$ Poissonian distributed latency used in the simulations. By about $70 \mathrm{~s}$ after OT, the latency simulations are exactly the same as the ideal case. This is not surprising, because latency will only alter the order in which data come in and are utilized; after some time, all the important data (i.e., the recording of peak ground motions) will be available. Latency does, however, 

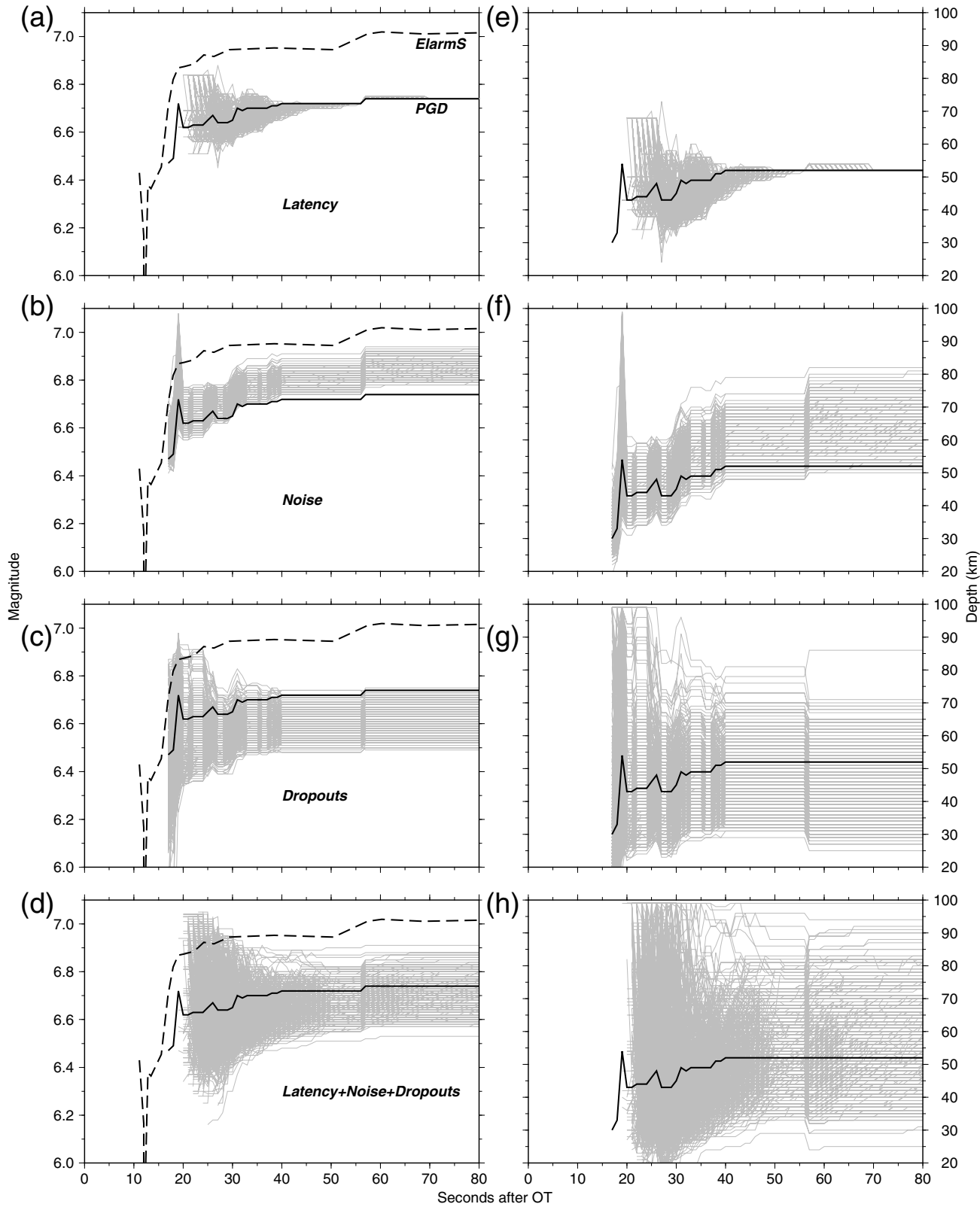

A Figure 4. (a-d) Magnitude and (e-h) depth as a function of time after origin time (OT) for the PGD simulations. The thick black lines represent the ideal solution with no noise, latency, or dropouts; the dashed lines on the left plots show the ElarmS magnitude estimates over time, and the thin gray lines represent different iterations in the four simulations, $(a, e)$ latency, $(b, f)$ noise, $(c, g)$ dropouts, and $(d$, h) latency + noise + dropouts.

delay the first-alert time from PGD by about $4-5 \mathrm{~s}$, thus delaying the first PGD estimate of magnitude.

The impact of noise is also not surprising. For the most part, noise causes the estimate of magnitude to be greater than in the ideal case, because the time series are just a superposition of the noise and the signal. Many of the stations have dynamic displacements that are not much greater than the noise level, so this low signal-to-noise ratio (SNR) can have a significant impact on the magnitude estimates. For example, a station that has a PGD of $1 \mathrm{~cm}$ at $100 \mathrm{~km}$ distance and an additional $1 \mathrm{~cm}$ of PGD added through noise will increase the magnitude es- timate for that station by 0.28 magnitude units; however, a station with a PGD of $10 \mathrm{~cm}$ at $100 \mathrm{~km}$ and an additional $1 \mathrm{~cm}$ of PGD added through noise will only increase the magnitude estimate by 0.04 magnitude units. Dropouts have the greatest impact on the magnitude estimates and tend to bias toward lower-magnitude estimates than the ideal case, due to the removal of peak ground motions; however, as evidenced by the histogram in Figure 5c, the vast majority of magnitude estimates at $30 \mathrm{~s}$ after OT in the simulation fall in a 0.2-magnitude band around $\mathbf{M}$ 6.6. The simulation looking at latency, noise, and dropouts has a wider band of possible magnitude 

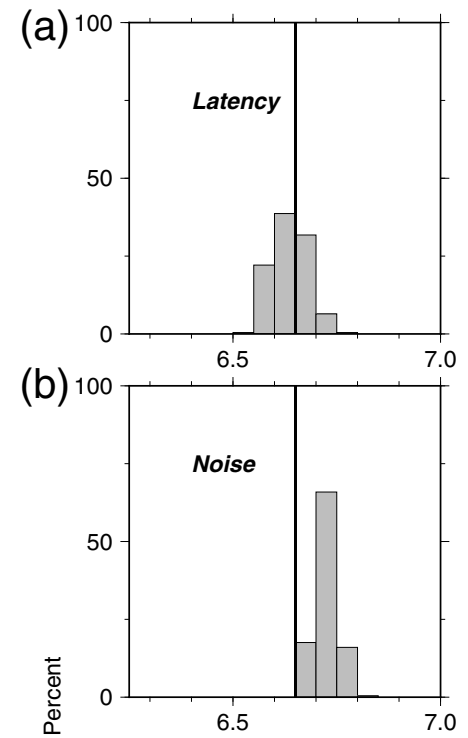

(c)
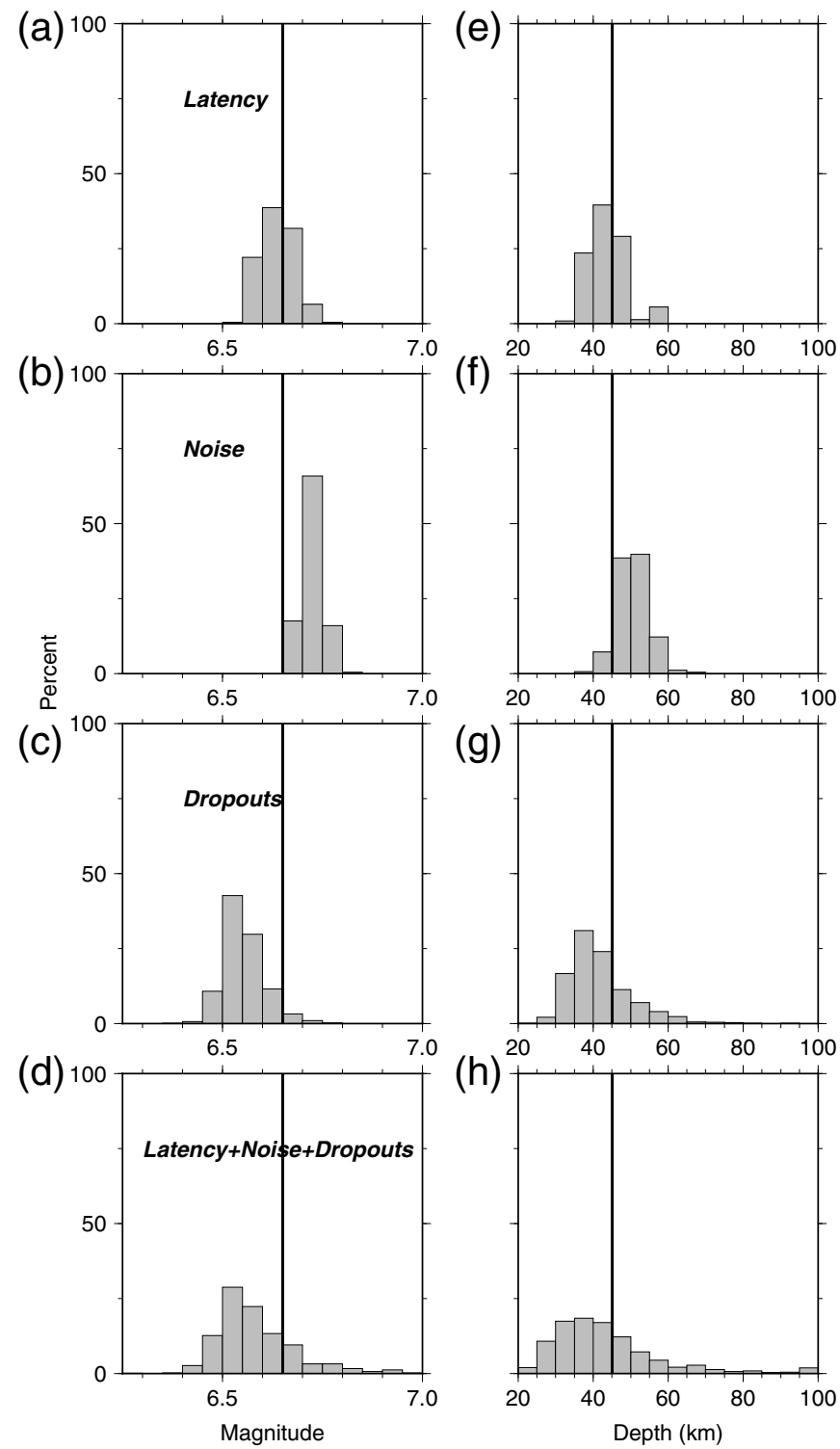

(f)

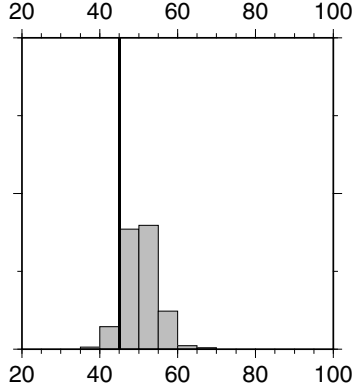

(g)

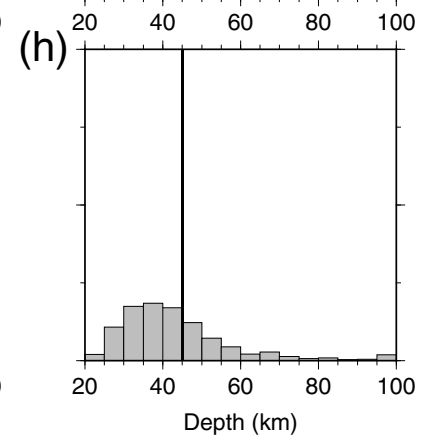

A Figure 5. Histograms of (a-d) magnitude and (e-h) depth for the four different PGD simulations at $30 \mathrm{~s}$ after OT. $(\mathrm{a}, \mathrm{e})$ Latency simulations, $(\mathrm{b}, \mathrm{f})$ noise, $(\mathrm{c}, \mathrm{g})$ dropouts, and $(\mathrm{d}, \mathrm{h})$ latency + noise + dropouts for magnitude and depth, respectively. The bin width for magnitude is 0.05 magnitude units and for depth is $5 \mathrm{~km}$. The vertical lines represent the optimal PGD solution at $30 \mathrm{~s}$ after $0 \mathrm{~T}$, magnitude 6.65 , and depth $45 \mathrm{~km}$.

estimates of about 0.3 magnitude units (Fig. 4d), but the result is still robust and only slightly larger than the previously published uncertainties of the PGD method (Crowell et al., 2013; Melgar et al., 2015).

The depth results have a much greater range of possible solutions, but like the magnitude estimates, the histograms in Figure 5 show the distributions are much tighter than they appear in Figure 4. Latency, once again, shows that it has the smallest impact on the results and eventually converges to the ideal solution by $70 \mathrm{~s}$. The noise simulations bias the depth estimates toward deeper depths, although all the simulations at

$30 \mathrm{~s}$ are between 40 and $65 \mathrm{~km}$ depth, which encompasses the previously published depth estimates (Bustin et al., 2004; Ichinose et al., 2004; Kao et al., 2008). Dropouts cause the greatest impact on the depth estimate, due to the removal of peak displacements that would impact the model fit. The distribution of depth measurements about the ideal solution for dropouts exhibits a skewing toward shallower depths. This is understandable, because the dropouts will impact the PGD measurements from the closest stations most, which will reduce the slope of the PGD-distance curve. However, most of the depth estimates fall between 30 and $60 \mathrm{~km}$ in the case of dropouts. The histogram for the case of latency, noise, and dropouts shows a similar shape to the dropout histogram. This implies that dropouts are the most important factor to consider, followed closely by noise. The effect of latency is minimal, and reducing latency will only have an impact on warning time and not on the stability of the magnitude and depth estimates.

\section{CMT-Driven Slip Inversion}

The CMT simulation results showing the magnitude, depth, strike, dip, and rake evolution as a function of time are shown in Figure 6. The first CMT (and finite-fault) estimate is available $38 \mathrm{~s}$ after OT for the ideal case, with magnitude $\mathbf{M} 7.3$ and strikes, dips, and rakes of $190^{\circ} / 319^{\circ}, 11^{\circ} / 82^{\circ}$, and $-40^{\circ} /-99^{\circ}$, respectively. After $50 \mathrm{~s}$, the CMT source parameters only vary a small amount and can be viewed as fully stable after this time. The ideal strikes, dips, and rakes at $100 \mathrm{~s}$ are $216^{\circ} / 344^{\circ}$, $16^{\circ} / 81^{\circ}$, and $-38^{\circ} /-102^{\circ}$, which is in general agreement with the USGS solution of $172^{\circ} / 347^{\circ}, 20^{\circ} / 71^{\circ}$, and $-85^{\circ} /-92^{\circ}$ and the input model of $350^{\circ}$ strike, $70^{\circ}$ dip, and $-90^{\circ}$ rake. We find an ideal source depth is $49 \mathrm{~km}$, which is in line with previous published results placing it at $\sim 50 \mathrm{~km}$ and the input model depth of $52 \mathrm{~km}$. Our final ideal CMT magnitude is M 7.1, larger than the actual magnitude of 6.8, but understandable given the simplifying assumptions of the method (point source) and the low number and low distribution of stations being used to compute the CMT.

For the CMT simulations, the impact of latency is similar to the PGD results, in that the variability in the source parameters is greater toward the beginning of the recordings, with a similar $5 \mathrm{~s}$ delay in the first-alert time. Noise does not lead to a bias, as was the case for the PGD simulations, but rather leads to a fairly even spread about the ideal solution across all source parameters. Dropouts on their own do not impact the CMT results at all. This is not surprising, because we average $10 \mathrm{~s}$ of data to determine the static offsets, so a few missing data points will not impact this average when there is no noise. If all data points are missing, G-FAST removes the station from further calculations, and any solution variability will be due to station distribution changes. Note, this in effect tests the temporally correlated dropouts scenario. However, the combined effects of noise and dropouts do provide appreciable variability as evidenced by the simulation under all conditions. The CMT simulations under all conditions provide insight into the statistical uncertainties of the CMT estimation. We compute the standard deviations of each parameter (magnitude, depth, strike, 

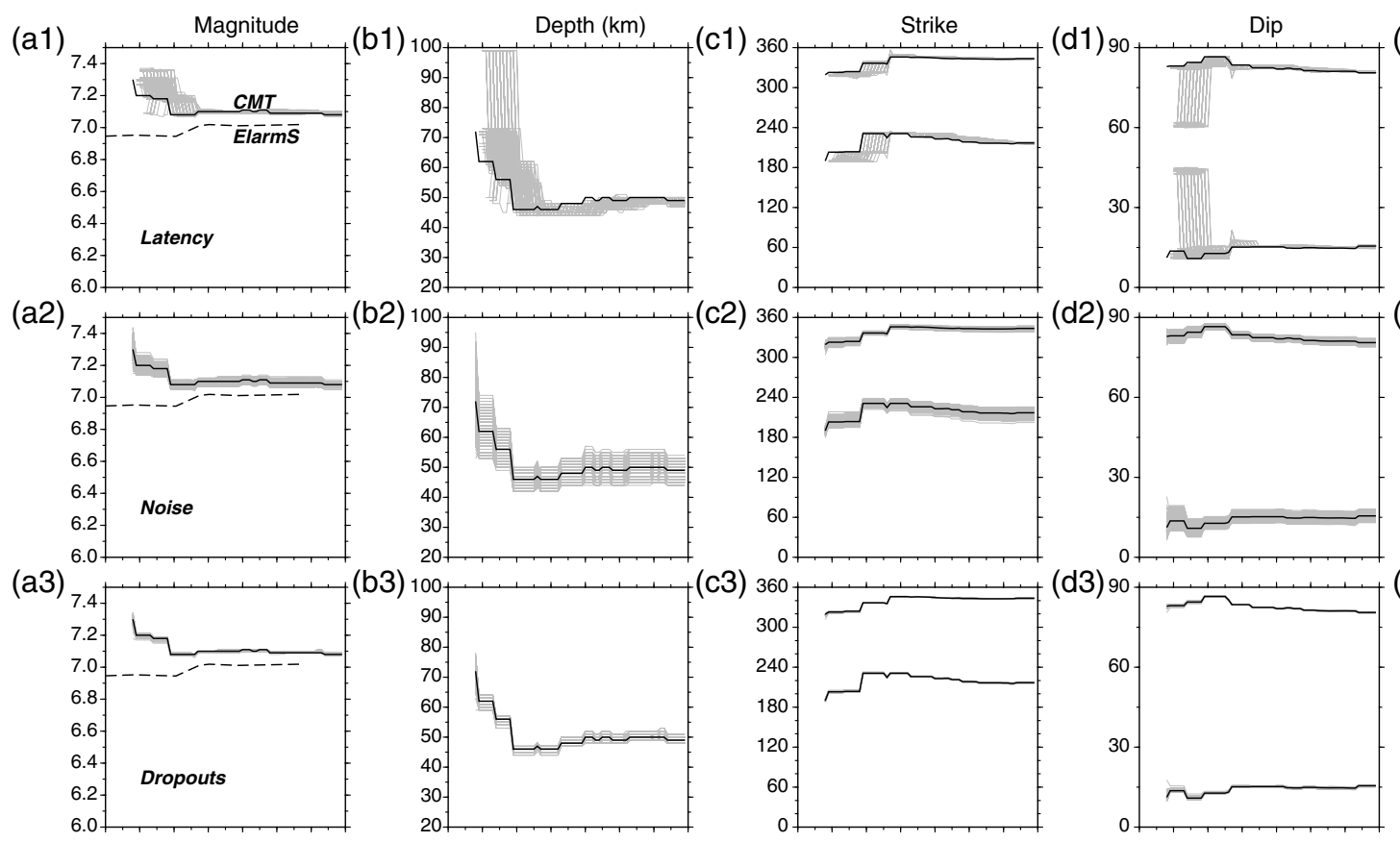

(d2)

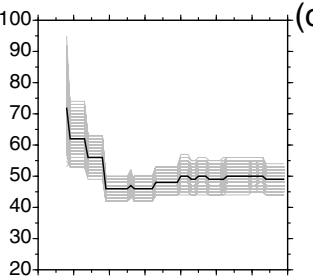

(b3)

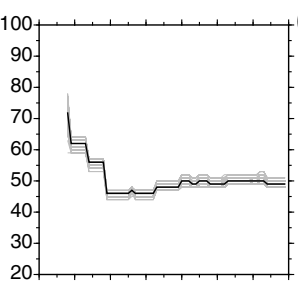

(c3) 360
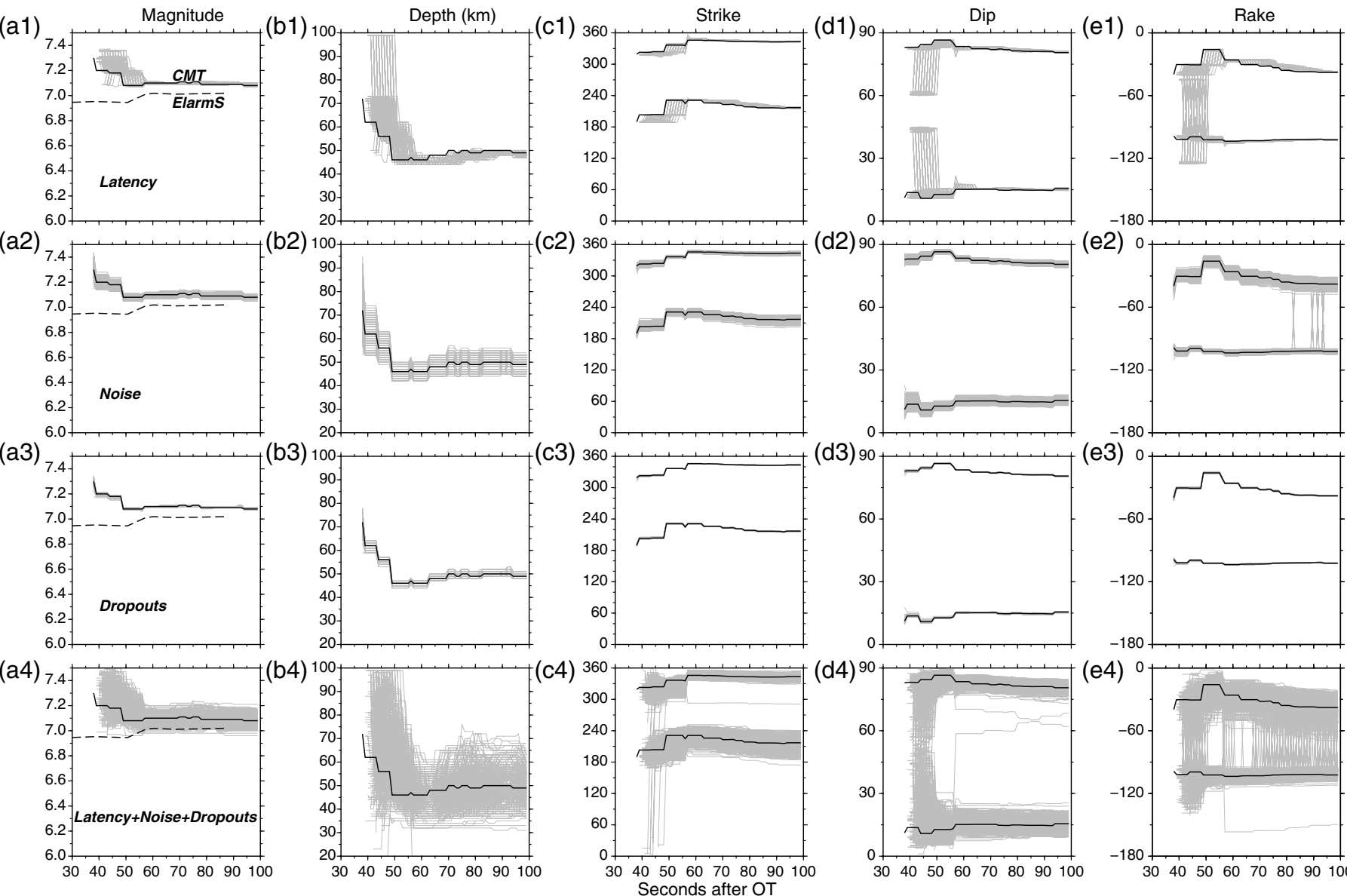

$(\mathrm{d} 4)$
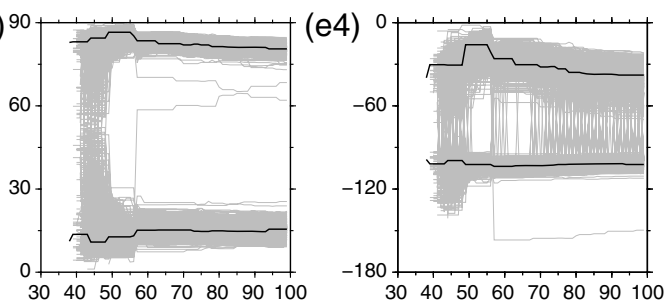

A Figure 6. Centroid Moment Tensor (CMT) simulation results for (a1-a4) magnitude, (b1-b4) depth, (c1-c4) strike, (d1-d4) dip, and (e1e4) rake. The thick black lines represent the ideal solution with no noise, latency, or dropouts, and the thin gray lines represent different iterations in the four simulations, latency (row 1), noise (row 2), dropouts (row 3), and latency + noise + dropouts (row 4).

dip, and rake) at $45 \mathrm{~s}$ after OT, because only an average of four stations are used to compute the CMT at that time. We find errors of 0.1 magnitude units, $17 \mathrm{~km}$ depth, $35.5^{\circ}$ in strike, $12.9^{\circ}$ in dip, and $22^{\circ}$ in rake. By $60 \mathrm{~s}$ after OT, these errors decrease by at least a factor of 3 .

The finite-fault magnitude evolution for the four simulations is shown in Figure 7. Figure 7 shows that the magnitude derived from the finite fault $(\sim 6.7)$ is much closer to the real magnitude, and the different simulations have similar behavior to the CMT simulations for which noise and all three conditions cause the greatest variability. The magnitude estimates from the finite-fault simulations have less variability than the CMT simulations. The optimal slip model and GPS fits at $100 \mathrm{~s}$ are shown in Figure 8. At $100 \mathrm{~s}$ after OT, only 15 of the stations are within the travel-time mask. The most troubling issue with the slip inversion is the preference for the shallowly dipping fault plane, which is not thought to be the correct plane and is not the input plane for the $f-k$ integration. Several other studies also struggled with fault-plane ambiguity for this event (Ichinose et al., 2004; Kao et al., 2008). Although the auxiliary fault plane is the preferred plane by the finite-fault analysis, the final VRs under the ideal case are $97 \%$ and $92 \%$, indicating that both fault models describe the data exceptionally well, and differences in shaking prediction are minimal. We attribute this problem to both the station density and distribution, with most stations on the eastern side of the fault, as well as to the low SNR of the stations in this study. The slip inversion without noise also selected the auxiliary fault plane as the preferred solution.

The bias in the finite-fault solution attributed to the skewed station distribution is analogous to an offshore event in which stations are on land toward the east of an event. In Figure 8, the current seismic and real-time GPS networks are shown by the gray symbols. To test whether or not we would expect issues with the fault-plane orientations with our current network, we forward modeled coseismic static displacements at the current GPS network stations and the old strong-motion network configuration due to slip on the main (steeply dipping) fault plane, using an even distribution of $1 \mathrm{~m}$ slip (reverse faulting), added random noise, and then inverted the static displacements onto both the main and auxiliary fault planes. Figure 9 shows the difference in the VR of the inversion 


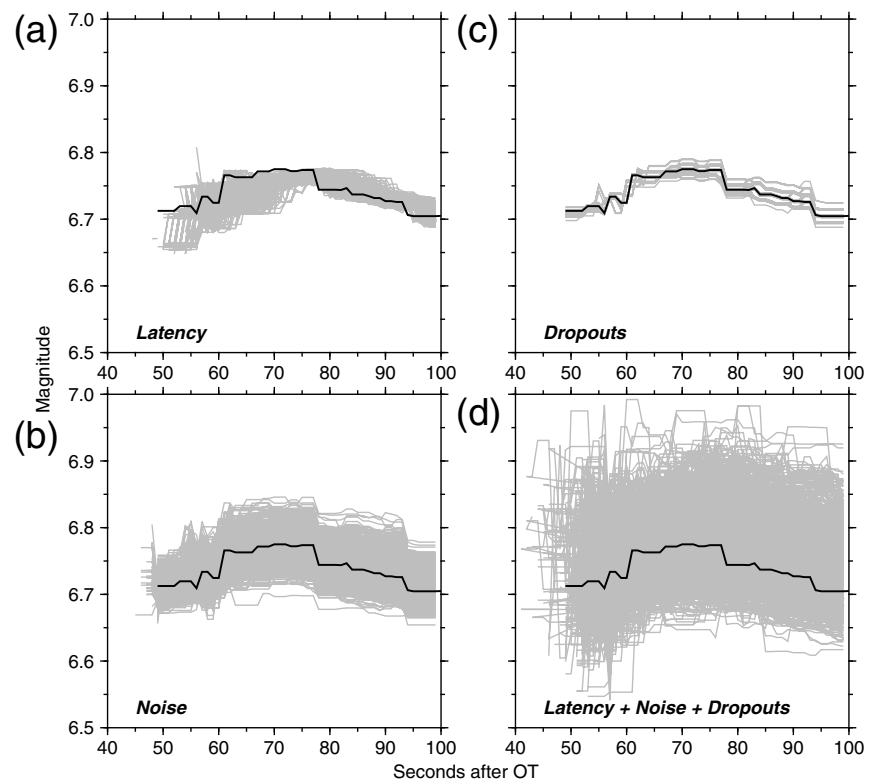

A Figure 7. Finite-fault magnitude estimates for the four simulations; (a) latency, (b) noise, (c) dropouts, and (d) latency + noise + dropouts. The thick black lines represent the ideal solution with no noise, latency, or dropouts, and the thin gray lines represent different iterations in the four simulations.

between the steeply dipping and shallowly dipping fault planes for 1000 iterations. With this even slip distribution, both network configurations choose the steeply dipping plane, but the current (denser) network configuration shows a greater spread in the VRs between the main and auxiliary fault-plane inversions than the older network configuration, by an average of $2 \%$. Considering that the VRs are already high, this $2 \%$ change, although small, is not an insignificant improvement. Although this result is not as satisfying as we would desire, for a mediumsized deep earthquake, the current network configuration still leads to an improvement in the fault-plane ambiguity, and greater station density would have a similar impact.

\section{FUTURE DIRECTIONS FOR GEODETIC EEW}

One limitation with G-FAST lies with the lower limit of detectability. With GPS data alone at regional distances, any event $\mathbf{M}<6$ will be difficult to measure due to noise. With seismogeodetic (GPS + strong-motion) data, Geng et al. (2013) suggested a lower limit of detectability of $\mathbf{M} \sim 5$ at regional distances, with dynamic motions visible at $\mathbf{M} 4.6$ in the near field; however, the seismic algorithms will effectively work to $\mathbf{M}<3$. Understanding how to weight magnitude estimates from G-FAST within the joint DecisionModule will be crucial going forward. The ShakeAlert DecisionModule takes the output of all the seismic algorithms and determines a best magnitude, location, and OT; modifying this to handle PGD magnitudes/depths and finite-fault information is complicated and an area of active research, which we discuss in some of the possibilities below. Grapenthin et al. (2014b) looked at after-
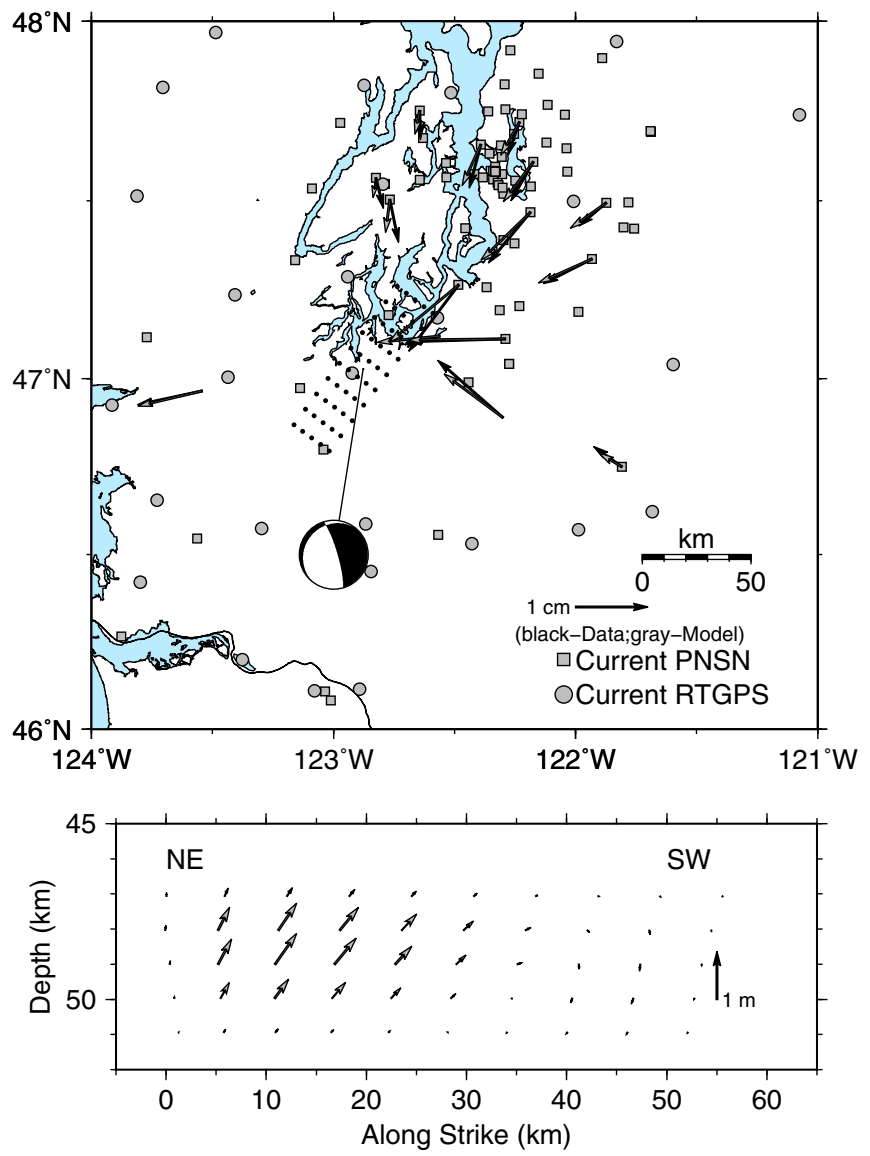

A Figure 8. The optimal slip model and coseismic fits at $100 \mathrm{~s}$ after OT. The optimal slip model is shown in the bottom panel, with the vectors indicating the motion of the hanging wall with respect to the foot wall. The map view shows the input coseismic displacements (black) and modeled displacements (gray). The gray circles show the locations of the current real-time Global Positioning System (GPS) stations and gray squares are the current strong-motion stations in the Pacific Northwest Seismic Network (PNSN). The focal mechanism plot in the map view is the ideal CMT computed at $100 \mathrm{~s}$, which the fault plane (black circles) is centered on. The color version of this figure is available only in the electronic edition.

shocks of the 2014 Napa earthquake and showed that G-larmS will consistently compute $\mathbf{M} \sim 6$ for small earthquakes due to noise, but the misfit of the models indicate that the magnitude estimates should not be trusted. Employing a minimum misfit criteria into the joint DecisionModule would help throw out unreliable source estimates from geodetic algorithms.

Network hardening, in the areas of latency and telemetry robustness, is very important for early warning stability. The simulations for dropouts showed the greatest variability for the PGD depth and magnitude estimates and indicate that improving telemetry links provides a high return on investment. Latencies, in the near field, are vital for reducing the no-warning-zone, both from seismic and geodetic algorithms, and can be reduced by improving telemetry, reducing packet sizes, or increasing station density. 


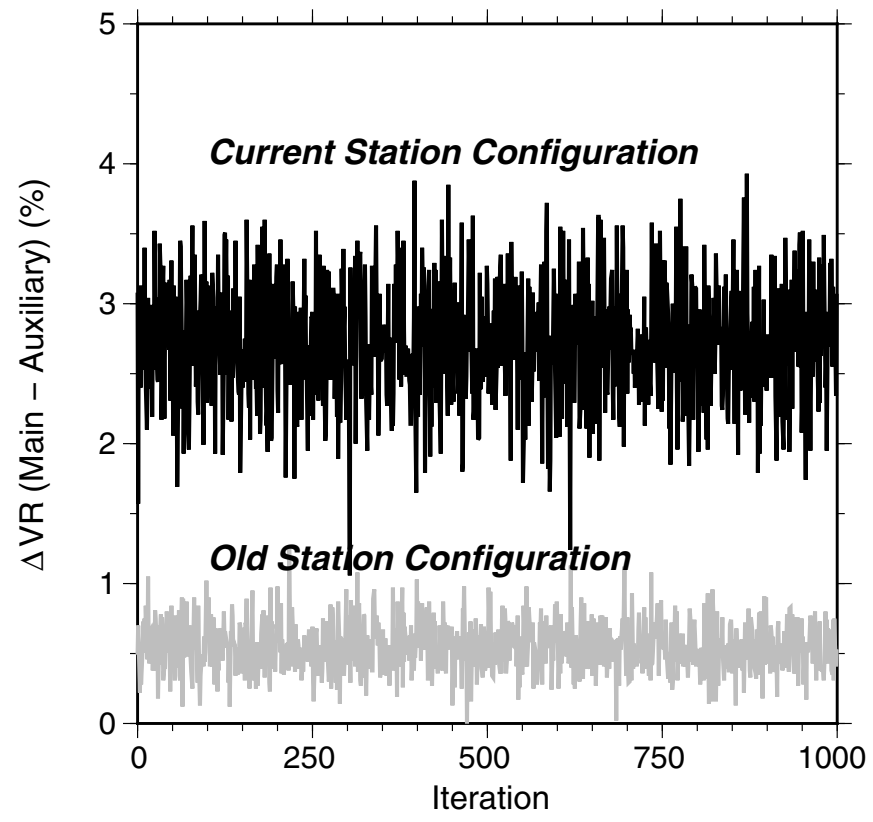

A Figure 9. Difference in VR between inversion on main and auxiliary fault planes for 1000 noise simulations with $1 \mathrm{~m}$ of dip slip on the steeply dipping fault plane (main). The inversion results using the current (2015) station configuration are shown in black and the old station configuration (2001; strong-motion stations) used in this study is shown in gray.

The most pressing issue going forward will be the seamless combination of magnitude and source estimates from the seismic algorithms (ElarmS, OnSite, VS, and FinDer [Böse et al., 2012]) and the geodetic algorithms (G-FAST, G-larmS, and BEFORES) and how to optimize the DecisionModule within ShakeAlert to use the most appropriate earthquake model. For example, the magnitude estimates from the seismic algorithms should be trusted with high confidence for lower-magnitude events, but the geodetic modules should be trusted more for higher magnitudes.

One must be careful, however, not to inadvertently bias the source characterization; if magnitude saturation occurs within the seismic algorithms, they will report a smaller magnitude and hence a higher weight than it should deserve in that instance. In addition, the use of finite faults versus point sources will drastically change the ground-motion prediction within the UserDisplay. The UserDisplay takes the magnitude, location, and timing information from the DecisionModule and computes the predicted ground motion and arrival time at the user's location. One example of a potential modification to the DecisionModule is to operate on each methodology independently and then run a weighted average of the groundmotion prediction from each method. This will still introduce biases to the final solution, so a detailed study of these effects would have to be performed to understand the potential impacts on EEW. One could also simply report a range of potential motions at a given location from all possible algorithms (i.e., MMI between VI and VIII); however, how this would be perceived by the general public is a complex issue, and lack of decisiveness will be considered a system weakness.

\section{CONCLUSIONS}

We have shown the utility of geodetic EEW for a moderatesized deep earthquake under Puget Sound. G-FAST is capable of providing timely, stable, and robust estimates of magnitude, depth, and source parameters under real-world conditions. Estimates of magnitude and depth from PGD scaling are quick and accurate; solutions for this simulation of the Nisqually earthquake are available by $22 \mathrm{~s}$ after OT, considering latency, and fully stable by $30 \mathrm{~s}$, converging to the correct magnitude and depth. The CMT results are available by $43 \mathrm{~s}$ after OT when considering latency and stabilize after $\sim 50 \mathrm{~s}$. The CMT nodal plane results are within $10^{\circ}$ in both strike and dip from the input model and the main fault-plane solution from the USGS and within several kilometers in depth. The final-magnitude estimate from the CMT is 0.3 magnitude units larger than postprocessed results. The slip inversion was not capable of ascertaining the correct fault plane for this deep event; however, with the current network configuration, we expect improvements in this capability. Previous studies have shown the ability for geodetic EEW to work for all earthquakes of societal relevance at regional distances, demonstrating that integrating high-rate geodetic observations into EEW systems worldwide is crucial for a complete and robust system.

\section{DATA AND RESOURCES}

Synthetic seismograms used in this study are available via request to the corresponding author B. W. C. Seismic data used can be obtained from the Incorporated Research Institutions for Seismology (IRIS) Data Management Center (www.iris. edu). Plots were created using the Generic Mapping Tools v.4.5.9 (www.soest.hawaii.edu/gmt; Wessel and Smith, 1998). The details of the following resources can be found at modified Mercalli intensity (MMI) VI-VII throughout the Puget Lowlands (http://earthquake.usgs.gov/earthquakes/shakemap/pn/ shake/01022818540, JavaScript Object Notation JSON protocol (http://www.json.org), and Python ObsPy package (http:// www.obspy.org). All the websites were last accessed January 2015. ¿

\section{ACKNOWLEDGMENTS}

We would like to thank John Langbein and Diego Melgar for thoughtful comments that improved the article. We also thank two anonymous reviewers and the Editor Zhigang Peng for helpful reviews. This work has been funded by the Gordon and Betty Moore Foundation Grant Number 663450 to University of Washington. 


\section{REFERENCES}

Allen, R. M., and A. Ziv (2011). Application of real-time GPS to earthquake early warning, Geophys. Res. Lett. 38, L16310, doi: 10.1029/ 2011 GL047947.

Altamimi, Z., L. Métivier, and X. Collilieux (2012). ITRF2008 plate motion model, J. Geophys. Res. 117, no. B07402, doi: 10.1029/ 2011JB008930.

Blewitt, G., C. Kreemer, W. C. Hammond, H.-P. Plag, S. Stein, and E. Okal (2006). Rapid determination of earthquake magnitude using GPS for tsunami warning systems, Geophys. Res. Lett. 33, L11309, doi: 10.1029/2006GL026145.

Bock, Y., D. Melgar, and B. W. Crowell (2011). Real-time strong-motion broadband displacements from collocated GPS and accelerometers, Bull. Seismol. Soc. Am. 101, no. 6, 2904-2925, doi: 10.1785/ 0120110007.

Böse, M., E. Hauksson, K. Solanki, H. Kanamori, Y.-M. Wu, and T. H. Heaton (2009). A new trigger criterion for improved real-time performance of onsite earthquake early warning in southern California, Bull. Seismol. Soc. Am. 99, no. 2A, 897-905, doi: 10.1785/ 0120080034.

Böse, M., T. H. Heaton, and E. Hauksson (2012). Real-time finite fault rupture detector (FinDer) for large earthquakes, Geophys. J. Int. 191, no. 2, 803-812, doi: 10.1111/j.1365-246X.2012.05657.x.

Böse, M., T. Heaton, and K. Hudnut (2013). Combining real-time seismic and GPS data for earthquake early warning (invited), American Geophysical Union, Fall Meeting 2013, abstract number G51B-05.

Brown, H. M., R. M. Allen, M. Hellweg, O. Khainovski, D. Neuhauser, and A. Souf (2011). Development of the ElarmS methodology for earthquake early warning: Realtime application in California and offline testing in Japan, Soil Dyn. Earthq. Eng. 31, no. 2, 188200, doi: 10.1016/j.soildyn.2010.03.008.

Bustin, A., R. D. Hyndman, A. Lambert, J. Ristau, J. He, H. Dragert, and M. Van der Kooij (2004). Fault parameters of the Nisqually earthquake determined from moment tensor solutions and the surface deformation from GPS and InSAR, Bull. Seismol. Soc. Am. 94, no. 2, 363-376, doi: 10.1785/0120030073.

Colombelli, S., R. M. Allen, and A. Zollo (2013). Application of real-time GPS to earthquake early warning in subduction and strike-slip environments, J. Geophys. Res. 118, no. 7, 3448-3461, doi: 10.1002/ jgrb.50242.

Crowell, B. W., Y. Bock, and D. Melgar (2012). Real-time inversion of GPS data for finite fault modeling and rapid hazard assessment, Geophys. Res. Lett. 39, L09305, doi: 10.1029/2012GL051318.

Crowell, B. W., Y. Bock, and M. Squibb (2009). Demonstration of earthquake early warning using total displacement waveforms from real time GPS networks, Seismol. Res. Lett. 80, no. 5, 772-782, doi: 10.1785/gssrl.80.5.772.

Crowell, B. W., D. Melgar, Y. Bock, J. S. Haase, and J. Geng (2013). Earthquake magnitude scaling using seismogeodetic data, Geophys. Res. Lett. 40, no. 23, 6089-6094, doi: 10.1002/ 2013 GL058391.

Cua, G., and T. Heaton (2007). The virtual seismologist (VS) method: A Bayesian approach to earthquake early warning, in Earthquake Early Warning Systems, P. Gasparini, G. Manfredi, and J. Zschau (Editors), Springer, Berlin, Germany, 97-130, doi: 10.1007/9783-540-72241-0_7.

Dreger, D., and A. Kaverina (2000). Seismic remote sensing for the earthquake source process and near-source strong shaking: A case study of the October 16, 1999 Hector Mine earthquake, Geophys. Res. Lett. 27, no. 13, 1941-1944.

Geng, J., Y. Bock, D. Melgar, B. W. Crowell, and J. S. Haase (2013). A new seismogeodetic approach applied to GPS and accelerometer observations of the 2012 Brawley seismic swarm: Implications for earthquake early warning, Geochem. Geophys. Geosyst. 14, no. 7, 2124-2142, doi: 10.1002/ggge.20144.
Genrich, J. F., and Y. Bock (2006). Instantaneous geodetic positioning with $10-50 \mathrm{~Hz}$ GPS measurements: Noise characteristics and implications for monitoring networks, J. Geophys. Res. 111, no. B03403, doi: 10.1029/2005JB003617.

Given, D. D., E. S. Cochran, T. Heaton, E. Hauksson, R. Allen, P. Hellweg, J. Vidale, and P. Bodin (2014). Technical implementation plan for the ShakeAlert production system: An earthquake early warning system for the west coast of the United States, U.S. Geol. Surv. Open-File Rept. 2014-1097, 25 pp., doi: 10.3133/ofr20141097.

Grapenthin, R., I. A. Johanson, and R. M. Allen (2014a). Operational real-time GPS-enhanced earthquake early warning, J. Geophys. Res. 119, no. 10, 7944-7965, doi: 10.1002/2014JB011400.

Grapenthin, R., I. Johanson, and R. M. Allen (2014b). The $2014 M_{\mathrm{w}} 6.0$ Napa earthquake, California: Observations from real-time GPS-enhanced earthquake early warning, Geophys. Res. Lett. 41, no. 23, 8269-8276, doi: 10.1002/2014GL061923.

Hartog, J. R., V. C. Kress, S. D. Malone, P. Bodin, J. E. Vidale, and B. W. Crowell (2016). Earthquake early warning: ShakeAlert in the Pacific Northwest, Bull. Seismol. Soc. Am. (accepted).

Hashima, A., Y. Takada, Y. Fukahata, and M. Matsu'ura (2008). General expressions for internal deformation due to a moment tensor in an elastic/viscoelastic multilayered half-space, Geophys. J. Int. 175, no. 3, 992-1012, doi: 10.1111/j.1365-246X.2008.03837.x.

Ichinose, G. A., H. K. Thio, and P. G. Somerville (2004). Rupture process and near-source shaking of the 1965 Seattle-Tacoma and 2001 Nisqually, intraslab earthquakes, Geophys. Res. Lett. 31, L10604, doi: $10.1029 / 2004 \mathrm{GL} 019668$.

Kao, H., K. Wang, R.-Y. Chen, I. Wada, J. He, and S. D. Malone (2008). Identifying the rupture plane of the 2001 Nisqually, Washington, earthquake, Bull. Seismol. Soc. Am. 98, no. 3, 1546-1558, doi: 10.1785/0120070160.

Kuyuk, H. S., R. M. Allen, H. Brown, M. Hellweg, I. Henson, and D. Neuhauser (2014). Designing a network-based earthquake early warning algorithm for California: ElarmS-2, Bull. Seismol. Soc. Am. 104, no. 1, 162-173, doi: 10.1785/0120130146.

Melgar, D., Y. Bock, and B. W. Crowell (2012). Real-time centroid moment tensor determination for large earthquakes from local and regional displacement records, Geophys. J. Int. 188, no. 2, 703-718, doi: 10.1111/j.1365-246X.2011.05297.x.

Melgar, D., Y. Bock, D. Sanchez, and B. W. Crowell (2013). On robust and reliable automated baseline corrections for strong motion seismology, J. Geophys. Res. 118, no. 3, 1177-1187, doi: 10.1002/jgrb.50135.

Melgar, D., B. W. Crowell, Y. Bock, and J. S. Haase (2013). Rapid modeling of the $2011 M_{\mathrm{w}} 9.0$ Tohoku-Oki earthquake with seismogeodesy, Geophys. Res. Lett. 40, no. 12, 2963-2968, doi: 10.1002/ grl.50590.

Melgar, D., B. W. Crowell, J. Geng, R. M. Allen, Y. Bock, S. Riquelme, E. Hill, M. Protti, and A. Ganas (2015). Earthquake magnitude calculations without saturation from the scaling of peak ground displacement, Geophys. Res. Lett. 42, no. 13, 5197-5205, doi: 10.1002/ 2015 GL064278.

Minson, S. E., J. R. Murray, J. O. Langbein, and J. S. Gomberg (2014). Real-time inversions for finite fault slip models and rupture geometry based on high-rate GPS data, J. Geophys. Res. 119, no. 4, 32013231, doi: 10.1002/2013JB010622.

Ohta, Y., T. Kobayashi, H. Tsushima, S. Miura, R. Hino, T. Takasu, H. Fujimoto, T. Iinuma, K. Tachibana, T. Demachi, et al. (2012). Quasi real-time fault model estimation for near-field tsunami forecasting based on RTK-GPS analysis: Application to the 2011 Tohoku-Oki earthquake ( $M_{\mathrm{w}}$ 9.0), J. Geophys. Res. 117, no. B02311, doi: 10.1029/2011JB008750.

Okada, Y. (1985). Surface deformation to shear and tensile faults in a half-space, Bull. Seismol. Soc. Am. 75, 1135-1154.

O'Toole, T. B., A. P. Valentine, and J. H. Woodhouse (2013). Earthquake source parameters from GPS-measured static displacements with potential for real-time application, Geophys. Res. Lett. 40, no. 1, 60-65, doi: 10.1029/2012GL054209. 
Wessel, P., and W. H. F. Smith (1998). New, improved version of generic mapping tools released, Eos Trans. $A G U$ 79, no. 47, 579, doi: 10.1029/98EO00426.

Wright, T. J., N. Houlié, M. Hildyard, and T. Iwabuchi (2012). Realtime, reliable magnitudes for large earthquakes from $1 \mathrm{~Hz}$ GPS precise point positioning: The 2011 Tohoku-Oki (Japan) earthquake, Geophys. Res. Lett. 39, L12302, doi: 10.1029/2012GL051894.

Zhu, L., and L. A. Rivera (2002). A note on the dynamic and static displacements from a point source in multi-layered media, Geophys. J. Int. 148, no. 3, 619-627, doi: 10.1046/j.1365-246X.2002.01610.x.

Zumberge, J. F., M. B. Heflin, D. C. Jefferson, M. M. Watkins, and F. H. Webb (1997). Precise point positioning for the efficient and robust analysis of GPS data from large networks, J. Geophys. Res. 102, no. B3, 5005-5017, doi: 10.1029/96JB03860.

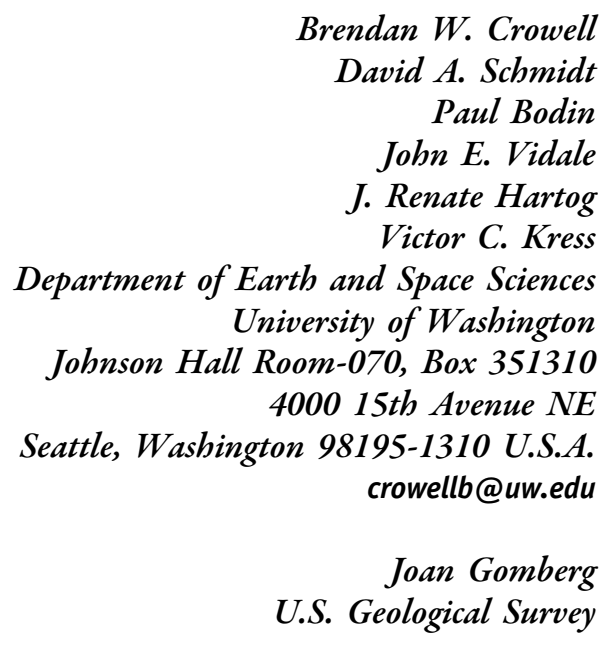

Earthquake Science Center University of Washington

Johnson Hall Room-070, Box 351310 4000 15th Avenue NE Seattle, Washington 98195-1310 U.S.A.

Timothy I. Melbourne Marcelo Santillan Department of Geological Sciences Central Washington University 400 E. University Way, MS 7418 Ellensburg, Washington 98926 U.S.A.

Sarah E. Minson U.S. Geological Survey Earthquake Science Center 345 Middlefield Road, MS 977 Menlo Park, California 94025-3591 U.S.A.

Dylan G. Jamison Department of Earth and Environmental Sciences University of Waterloo 200 University Avenue West Waterloo, Ontario Canada N2L $3 G 1$

Published Online 8 June 2016 